\title{
Long-term record of aerosol optical properties and chemical composition from a high-altitude site (Manora Peak) in Central Himalaya
}

\author{
K. Ram ${ }^{1}$, M. M. Sarin ${ }^{1}$, and P. Hegde ${ }^{2}$ \\ ${ }^{1}$ Physical Research Laboratory, Ahmedabad - 380 009, India \\ ${ }^{2}$ Space Physics Laboratory, Trivandrum - 695022, India \\ Received: 5 February 2010 - Published in Atmos. Chem. Phys. Discuss.: 23 March 2010 \\ Revised: 24 October 2010 - Accepted: 21 November 2010 - Published: 13 December 2010
}

\begin{abstract}
A long-term study, conducted from February 2005 to July 2008, involving chemical composition and optical properties of ambient aerosols from a high-altitude site (Manora Peak: $29.4^{\circ} \mathrm{N}, 79.5^{\circ} \mathrm{E}, \sim 1950 \mathrm{~m}$ a.s.l.) in the central Himalaya is reported here. The total suspended particulate (TSP) mass concentration varied from 13 to $272 \mu \mathrm{g} \mathrm{m}^{-3}$ over a span of 42 months. Aerosol optical depth (AOD) and TSP increase significantly during the summer (AprilJune) due to increase in the concentration of mineral dust associated with the long-range transport from desert regions (from the middle-East and Thar Desert in western India). The seasonal variability in the carbonaceous species (EC, OC) is also significantly pronounced, with lower concentrations during the summer and monsoon (July-August) and relatively high during the post-monsoon (September-November) and winter (December-March). On average, total carbonaceous aerosols (TCA) and water-soluble inorganic species (WSIS) contribute nearly 25 and $10 \%$ of the TSP mass, respectively. The WSOC/OC ratios range from 0.36 to 0.83 (average: $0.55 \pm 0.15$ ), compared to lower ratios in the IndoGangetic Plain (range: $0.35-0.40$ ), and provide evidence for the enhanced contribution from secondary organic aerosols. The mass fraction of absorbing EC ranged from less than a percent (during the summer) to as high as $7.6 \%$ (during the winter) and absorption coefficient ( $b_{\mathrm{abs}}$, at $678 \mathrm{~nm}$ ) varied between 0.9 to $33.9 \mathrm{Mm}^{-1}\left(1 \mathrm{Mm}^{-1}=10^{-6} \mathrm{~m}^{-1}\right)$. A significant linear relationship between $b_{\mathrm{abs}}$ and $\mathrm{EC}\left(\mu \mathrm{gC} \mathrm{m}{ }^{-3}\right)$ yields a slope of $12.2( \pm 2.3) \mathrm{m}^{2} \mathrm{~g}^{-1}$, which is used as a measure of the mass absorption efficiency $\left(\sigma_{\mathrm{abs}}\right)$ of EC.
\end{abstract}

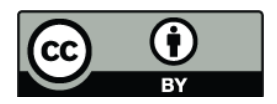

Correspondence to: M. M. Sarin (sarin@prl.res.in)

\section{Introduction}

The rapid urbanization and industrial growth in the south and south-east Asia have lead to a substantial increase in the atmospheric abundance of aerosols on a regional scale (Adhikary et al., 2007; Jethva et al., 2005; Rengarajan et al., 2007). The formation of Atmospheric Brown Cloud (ABC), a thick and grey-brownish haze over the Indo-Gangetic Plain (IGP) and the Indian Ocean during the late NE-monsoon (January-March) has been a subject of significant debate in recent years (Bonasoni et al., 2010; Ramanathan and Carmichael, 2008; Ramanathan et al., 2005; Ramanathan and Ramana, 2005). The high atmospheric aerosol loading over south-east Asia, persistent throughout the year, can further induce dimming of the solar radiation at the surface and counter the influence of warming caused by greenhouse gases (Carmichael et al., 2009).

Black carbon (BC), a major absorbing species in the atmosphere with a warming potential of $\sim 55 \%$ in comparison to that of $\mathrm{CO}_{2}$ (Carmichael et al., 2009), plays a significant role in Earth's radiation budget, regional climate and hydrological cycle (Jacobson, 2001; Lelieveld et al., 2001; Menon et al., 2002; Ramanathan and Carmichael, 2008). Based on the real-time measurements and retrieval of the data from satellites, recent studies have inferred that BC mass concentration contributes $\sim 5-10 \%$ of the total aerosol optical depth (AOD) over the central Himalaya (Pant et al., 2006; Ramana et al., 2004) and relatively low single scattering albedo (SSA) suggests the absorbing nature of aerosols (Gautam et al., 2009; Hyvärinen et al., 2009; Ramana et al., 2004; Sagar et al., 2004). Furthermore, it has been argued that an increase in the atmospheric concentration of $\mathrm{BC}$ and its deposition to snow surfaces can decrease the snow-albedo leading

Published by Copernicus Publications on behalf of the European Geosciences Union. 
to an enhancement in the melting of the Himalayan glaciers (Menon et al., 2010). Yasunari et al. (2010) have reported that deposition of $\mathrm{BC}$ aerosols during the summer/ premonsoon (April-June) can cause a reduction of $\sim 2-5 \%$ in the snow-albedo which can lead to an increase of $\sim 70-204 \mathrm{~mm}$ runoff of water drainage. Thus, a detailed understanding and knowledge of the chemical composition of aerosols, their size-distribution and optical properties (absorption coefficient, SSA and AOD) is of utmost interest for the assessment of aerosol radiative forcing and air-quality over the Himalayan region.

We present here a comprehensive data set acquired during Feb 2005 to July 2008 through measurements of atmospheric concentrations of organic and elemental carbon (OC and $\mathrm{EC}$ ), water-soluble $\mathrm{OC}$ (WSOC) and a suite of inorganic species $\left(\mathrm{K}^{+}, \mathrm{Ca}^{2+}, \mathrm{NO}_{3}^{-}\right.$and $\left.\mathrm{SO}_{4}^{2-}\right)$, together with $\mathrm{OC} / \mathrm{EC}$ and WSOC/OC ratios, from a high-altitude site (Manora Peak, $\sim 1950 \mathrm{~m}$ a.s.l.) in the central Himalaya. In addition, measurements of aerosol optical depth (AOD), absorption coefficient $\left(b_{\mathrm{abs}}\right)$ and mass absorption efficiency $\left(\sigma_{\mathrm{abs}}\right)$ of EC form an integral part of this study. Our choice of sampling from a high-altitude site is advantageous in order to study the long-range transport of organic and inorganic aerosols.

\section{Methodology}

\subsection{Ambient aerosol sampling}

Ambient aerosols were collected (from February 2005 to July 2008) on to pre-combusted (at $650^{\circ} \mathrm{C}$ for $\sim 6 \mathrm{~h}$ ) tissuquartz filters (PALLFLEX ${ }^{\mathrm{TM}}$, 2500QAT-UP; size: $20.0 \times 25.4 \mathrm{~cm}^{2}$ ) using a high-volume sampler, operated at a flow rate of $1.0 \pm 0.1 \mathrm{~m}^{3} \mathrm{~min}^{-1}$ (Ram et al., 2008). Each sample was integrated for a time-period ranging from $15-20 \mathrm{~h}$ to collect adequate aerosol mass on the filters. Initially, sampling frequency of one sample every two weeks was maintained, and later increased to one sample per week during December 2007-March 2008. A total of 86 aerosol samples were collected during the sampling period spanned over 42 months. Of these, 38 samples were collected during the wintertime (December-March), 20 samples during the summer/premonsoon (April-June), 17 samples during the monsoon (July-September) and 11 samples during the postmonsoon months (October-November).

\section{Site description and meteorological details}

Manora Peak $\left(29.4^{\circ} \mathrm{N}, 79.5^{\circ} \mathrm{E}\right)$ is located at an altitude of $\sim 1950 \mathrm{~m}$ a.s.l. in the Shivalik mountain range along the central Himalaya (Fig. 1). The sampling site is relatively free from large scale anthropogenic activities within the immediate vicinity. The major sources of carbonaceous aerosols include emissions from regional scale biomass burning and transport of pollutants from the Indo-Gangetic Plain (IGP) during the wintertime (December-February) (Dumka et al., 2006). During premonsoon (April-June), long-range transport of mineral aerosols (Fig. 1) dominate the atmospheric loading with a relative decrease in concentrations of carbonaceous species due to decrease in the source strength of biomass burning emission (Ram et al., 2008). The relative source strength of mineral dust and carbonaceous aerosols impart a strong seasonal and inter-annual variability in the chemical and optical properties of ambient aerosols at Manora Peak.

The meteorological parameters (rainfall, wind speed and direction) regulate the atmospheric abundance of aerosols, their chemical composition and optical properties. The wet scavenging of chemical species from the atmosphere is related to the amount of rainfall and, thus, dictates their seasonal and intra-annual variability. The rainfall over northern India mainly occurs during the south-west monsoon (late June to September) (Fig. 2d). The major wind regime during the summertime passes over Desert regions in the middleEast and the Thar Desert (in western India), and serves as a potential source of mineral dust to the central Himalaya (Hegde et al., 2007; Prasad and Singh, 2007; Ram et al., 2008). The boundary layer dynamics also play an important role in dictating the ambient concentrations of chemical species. Hegde et al. (2008) have reported that boundary layer height (BLH) is relatively shallow during the postmonsoon compared to that in the premonsoon season. The BLH for the four seasons, winter, premonsoon, monsoon and post-monsoon during 2006-07, are 1300, 1450, 1000 and $600 \mathrm{~m}$, respectively (Hegde et al., 2008). It is relevant to state that the measurement of the planetary boundary layer (PBL) thickness was made at Manora Peak and refers to local PBL height. Thus, the PBL height of $1300 \mathrm{~m}$ corresponds to an altitude of $3300 \mathrm{~m}$. During the wintertime, relatively low temperatures, poor thermal convection and shallow boundary layer height confine the aerosols in the lower atmosphere and thus, lead to an increase in the concentrations of carbonaceous species ( $\mathrm{OC}$ and $\mathrm{EC}$ ). The meteorological data consisting of rainfall, temperature, wind speed and wind direction, during the sampling period, are shown in Fig. 2.

\section{Analytical methods}

The total suspended particulate (TSP) mass was ascertained by weighing the filters (before and after the sampling) at constant temperature $\left(22 \pm 2{ }^{\circ} \mathrm{C}\right)$ and relative humidity $(35 \pm 5 \%)$. The concentration of carbonaceous species (EC, $\mathrm{OC}$ ) in atmospheric aerosols are assessed on the EC-OC analyzer (Sunset Laboratory, Tigard, OR) using thermo-optical transmittance (TOT) protocol (Ram et al., 2008; Rengarajan et al., 2007). The carbonate carbon (CC) concentrations were obtained by manual integration of the EC-OC thermogram of aerosol samples between 210-220 and 280-290 s (Ram et al., 2008). The CC peak in the EC-OC thermogram was 


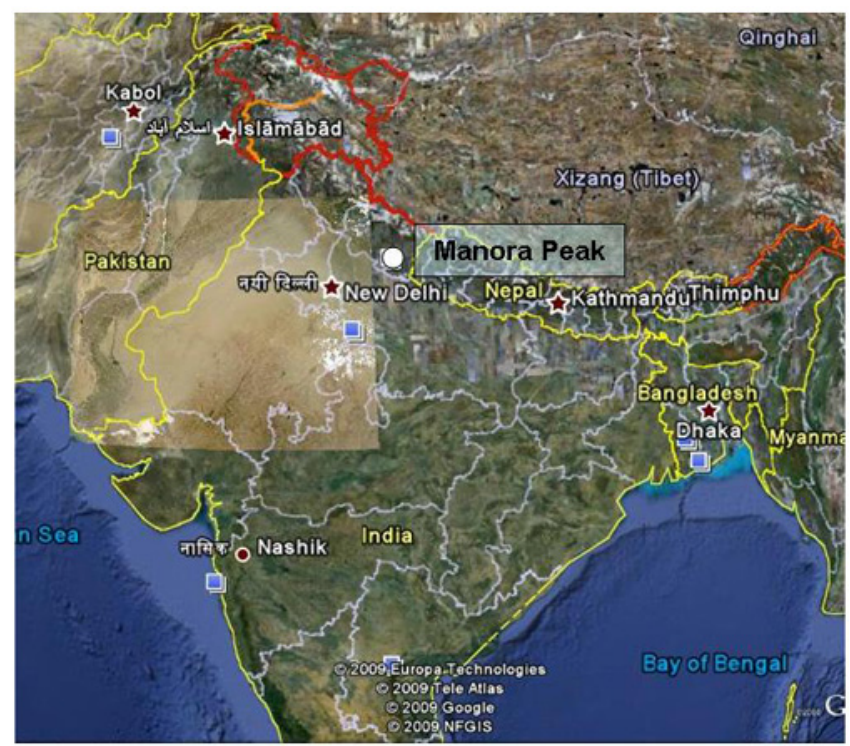

Fig. 1. The sampling site, Manora Peak (white circle) located at the foot-hills of central Himalaya. A major dust storm that occurred on 12 June 2006 over the Indus Valley (along the border between Pakistan and India) is also shown in the picture (brown rectangle). This dust-storm had resulted in the high TSP abundances and AOD values at Manora Peak. The event was captured by the Moderate Resolution Imaging Spectroradiometer (MODIS) flying onboard NASA's Aqua satellite on 12 June 2006 (http://earthobservatory. nasa.gov) and was combined with the Google Earth.

confirmed by de-carbonizing aerosol samples with $6 \mathrm{M} \mathrm{HCl}$ fumes in a desiccator (for $\sim 3 \mathrm{~h}$ ), running the acidified aliquot and comparing the thermograph with an unacidified sample (Cachier et al., 1989). Simultaneously, blank filters were also run and all the reported $\mathrm{OC}$ concentrations are corrected for the OC blank $\left(\sim 0.8 \mu \mathrm{gC} \mathrm{m}{ }^{-3}\right)$ and carbonate carbon (CC). The initial transmittance, ratio of the transmitted radiation (I) to the incident radiation $\left(\mathrm{I}_{0}\right)$, measured using a $678 \mathrm{~nm}$ laser source is used to define the split-point between $\mathrm{OC}$ and EC. The optical-attenuation [ATN; ATN $=-100 \times \ln \left(\mathrm{I} / \mathrm{I}_{0}\right)$ ] measurements at $678 \mathrm{~nm}$ in the EC-OC analyzer have been used for the determination of absorption coefficient $\left(b_{\mathrm{abs}}\right)$ and mass absorption efficiency of EC $\left(\sigma_{\mathrm{abs}}\right)$. The propagated root-sum-square error for the determination of $b_{\mathrm{abs}}$ and $\sigma_{\mathrm{abs}}$ is estimated to be of the order of $\sim 23$ and $32 \%$, respectively. The experimental details and the associated uncertainties in the determination of absorption properties are described in our recent publication (Ram and Sarin, 2009).

The measurement of WSOC are performed using a total organic carbon (TOC) analyzer (Shimadzu, model TOC$5000 \mathrm{~A}$ ) according to the protocol described in Ram and Sarin (2010). Briefly, one-fourth filter $\left(\sim 105 \mathrm{~cm}^{2}\right.$ area $)$ is soaked in $50 \mathrm{ml}$ de-ionized water (resistivity: $18.2 \mathrm{M} \Omega \mathrm{cm}$ ) and ultrasonicated for $\sim 1-2 \mathrm{~h}$. The resulting water-extract is filtered, transferred to a pre-cleaned glass vial and analyzed

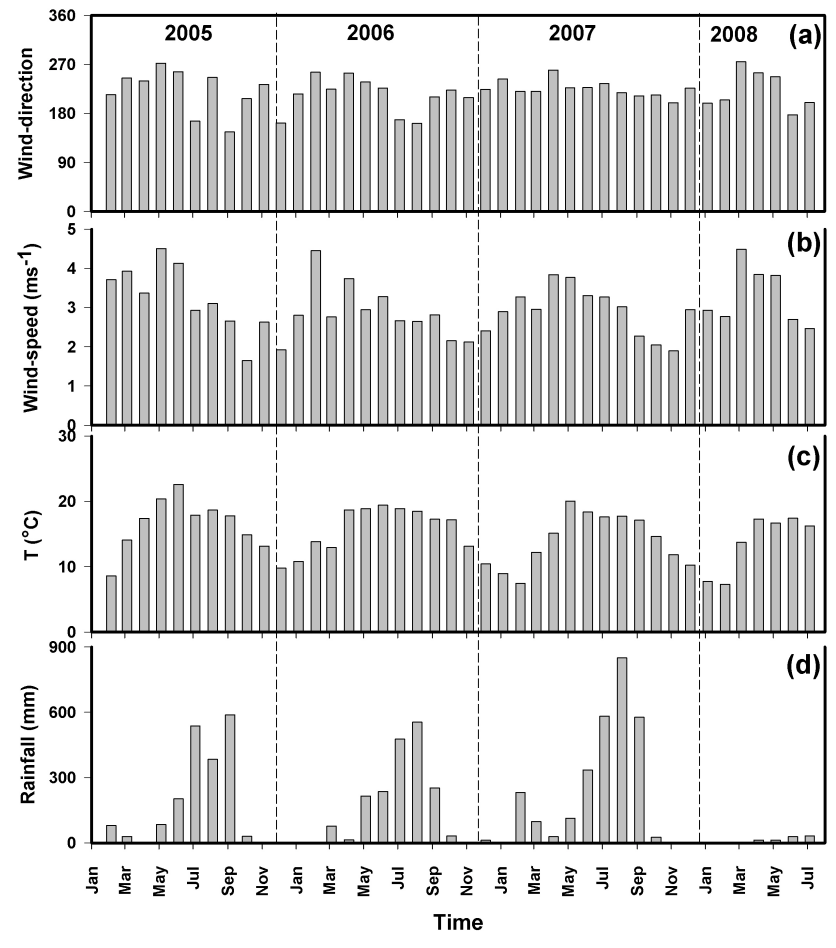

Fig. 2. The monthly average meteorological data for rain fall, temperature, wind speed and wind-direction during the sampling period (February 2005-July 2008).

for the WSOC content. The analysis of water-soluble cations $\left(\mathrm{K}^{+}\right.$and $\left.\mathrm{Ca}^{2+}\right)$ and anions $\left(\mathrm{SO}_{4}^{2-}\right.$ and $\left.\mathrm{NO}_{3}^{-}\right)$is performed on the water-extracts (similar to that used for the WSOC analysis) using an ion-chromatograph (Dionex) as per the standard procedure described in our earlier publications (Kumar et al., 2008; Rengarajan et al., 2007). Simultaneously, blank filters are also analyzed in order to correct for the contribution of WSOC, cations and anions from the filters.

\section{Results and discussion}

\subsection{Total suspended particulate (TSP), OC and EC mass concentrations and temporal variability in aerosol chemical composition}

The total suspended particulate (TSP) mass at Manora Peak ranges from 13 to $272 \mu \mathrm{g} \mathrm{m}^{-3}$ during the sampling period (February 2005-July 2008) (Fig. 3a). The temporal variability in TSP mass is attributed to the varying contribution from mineral and carbonaceous aerosols. The contribution of mineral dust (as evident from an increase in the concentrations of carbonate carbon and $\mathrm{Ca}^{2+}$; Figs. $3 \mathrm{~b}$, c respectively), due to the long-range transport from the Thar Desert (in western India) and the middle-East, dominates during premonsoon/summer (April-June). The concentrations of OC and $\mathrm{EC}$ at Manora Peak varied from 0.4 to $22.3 \mu \mathrm{gC} \mathrm{m}{ }^{-3}$ (1.9 to 


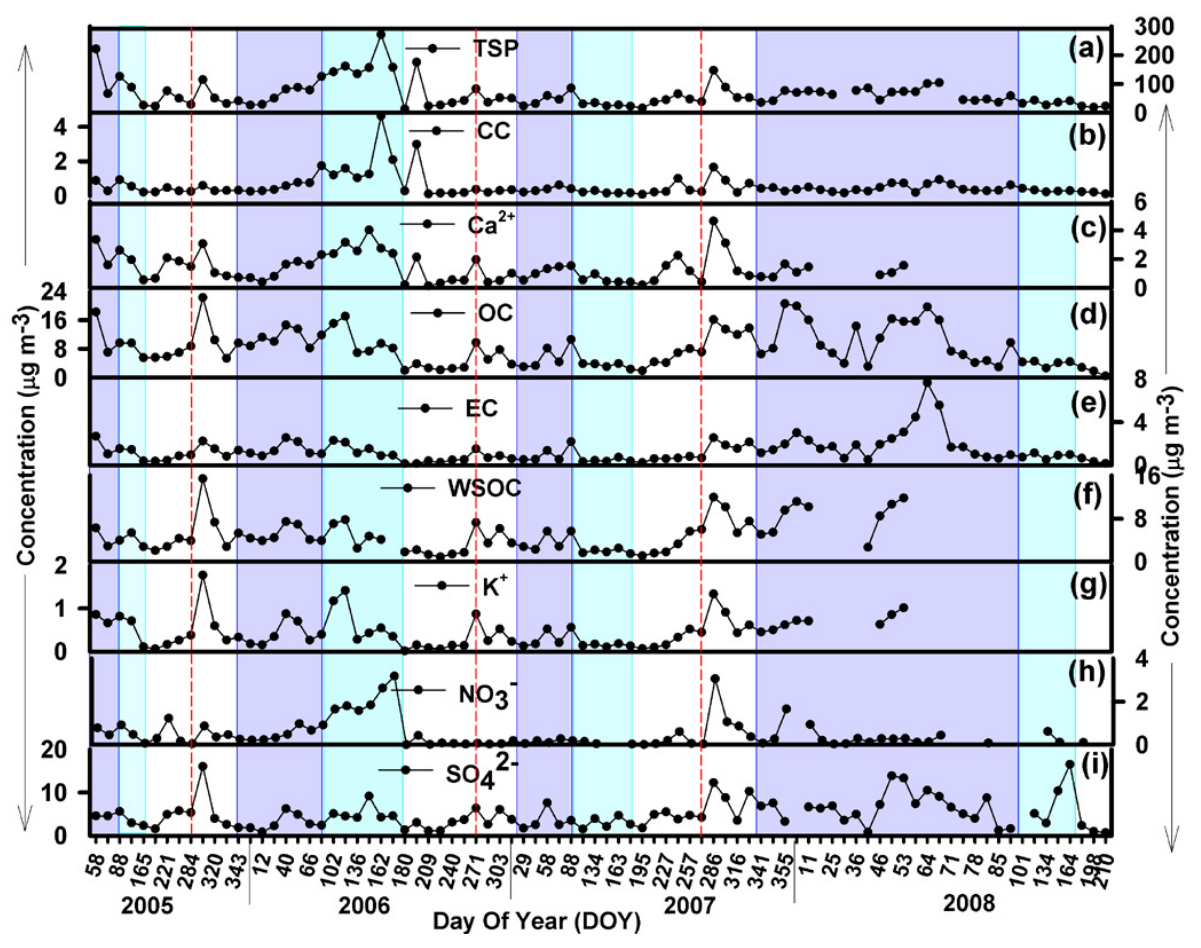

Fig. 3. Temporal variability in the abundances of (a) total suspended particulate (TSP) matter, (b) carbonate carbon $(\mathrm{CC}),(\mathbf{c}) \mathrm{Ca}^{2+},(\mathbf{d}) \mathrm{OC}$ (e) EC, (f) WSOC, (g) $\mathrm{K}^{+}$(h) $\mathrm{NO}_{3}^{-}$and (i) $\mathrm{SO}_{4}^{2-}$ during the sampling period. The light blue and cyan shaded areas represent winter and premonsoon, respectively. The dashed-line (red) separates the monsoon and post-monsoon.

Table 1. The monthly average concentrations $( \pm 1 \sigma)$ of chemical constituents and optical parameters in aerosols at Manora Peak under ambient conditions during February 2005-July 2008. The concentrations in standard conditions can be obtained by multiplying the data in table by a factor of 1.3 .

\begin{tabular}{|c|c|c|c|c|c|c|c|c|c|c|c|c|c|}
\hline Month & $n$ & TSP & AOD* & $b_{\mathrm{abs}}$ & $\sigma_{\mathrm{abs}}$ & $\mathrm{EC}$ & OC & WSOC & WSOC/OC & $\mathrm{NO}_{3}^{-}$ & $\mathrm{SO}_{4}^{2-}$ & $\mathrm{K}^{+}$ & $\mathrm{Ca}^{2+}$ \\
\hline & & $\mu \mathrm{g} \mathrm{m}^{-3}$ & & $\mathrm{Mm}^{-1}$ & $\mathrm{~m}^{2} \mathrm{~g}^{-1}$ & $\mu \mathrm{gCm} \mathrm{m}^{-3}$ & $\mu \mathrm{gCm} \mathrm{m}^{-3}$ & $\mu \mathrm{gC} \mathrm{m}{ }^{-3}$ & & $\mu \mathrm{g} \mathrm{m}^{-3}$ & $\mu \mathrm{g} \mathrm{m}^{-3}$ & $\mu \mathrm{g} \mathrm{m}^{-3}$ & $\mu \mathrm{g} \mathrm{m}^{-3}$ \\
\hline Jan & 6 & $52 \pm 22$ & $0.06 \pm 0.04$ & $13.9 \pm 8.2$ & $11.3 \pm 0.8$ & $1.3 \pm 0.8$ & $9.3 \pm 4.4$ & $5.2 \pm 3.3$ & $0.57 \pm 0.24$ & $0.4 \pm 0.4$ & $2.9 \pm 2.6$ & $0.3 \pm 0.3$ & $0.8 \pm 0.5$ \\
\hline Feb & 12 & $76 \pm 49$ & $0.11 \pm 0.07$ & $18.9 \pm 7.9$ & $10.5 \pm 2.2$ & $1.9 \pm 0.9$ & $10.6 \pm 5.5$ & $6.1 \pm 3.2$ & $0.56 \pm 0.15$ & $0.3 \pm 0.3$ & $6.1 \pm 4.4$ & $0.6 \pm 0.3$ & $1.4 \pm 0.8$ \\
\hline Mar & 14 & $86 \pm 32$ & $0.18 \pm 0.15$ & $12.7 \pm 4.5$ & $12.6 \pm 4.7$ & $1.5 \pm 0.5$ & $8.8 \pm 3.1$ & $3.8 \pm 1.0$ & $0.46 \pm 0.11$ & $0.6 \pm 0.3$ & $3.6 \pm 1.3$ & $0.5 \pm 0.3$ & $1.9 \pm 0.5$ \\
\hline Apr & 6 & $106 \pm 59$ & $0.25 \pm 0.09$ & $13.9 \pm 5.7$ & $11.4 \pm 3.2$ & $1.4 \pm 0.8$ & $9.1 \pm 5.8$ & $5.3 \pm 2.7$ & $0.46 \pm 0.06$ & $1.0 \pm 0.8$ & $3.5 \pm 1.6$ & $0.9 \pm 0.2$ & $2.0 \pm 1.1$ \\
\hline May & 6 & $87 \pm 68$ & $0.31 \pm 0.12$ & $11.5 \pm 6.6$ & $14.0 \pm 3.5$ & $0.8 \pm 0.5$ & $4.7 \pm 2.0$ & $2.7 \pm 1.3$ & $0.51 \pm 0.12$ & $1.2 \pm 1.0$ & $4.9 \pm 3.0$ & $0.2 \pm 0.1$ & $2.0 \pm 1.6$ \\
\hline Jun & 8 & $86 \pm 111$ & $0.33 \pm 0.03$ & $9.3 \pm 4.6$ & $14.5 \pm 3.6$ & $0.6 \pm 0.2$ & $4.8 \pm 2.7$ & $2.4 \pm 1.1$ & $0.58 \pm 0.09$ & $1.5 \pm 1.6$ & $3.3 \pm 1.1$ & $0.2 \pm 0.2$ & $1.2 \pm 1.1$ \\
\hline Jul & 7 & $55 \pm 68$ & $0.16 \pm 0.11$ & $4.1 \pm 2.3$ & $12.2 \pm 3.5$ & $0.3 \pm 0.2$ & $2.9 \pm 1.8$ & $1.5 \pm 0.5$ & $0.44 \pm 0.10$ & $0.2 \pm 0.2$ & $2.5 \pm 1.5$ & $0.1 \pm 0.05$ & $0.7 \pm 0.8$ \\
\hline Aug & 5 & $49 \pm 21$ & $0.16 \pm 0.04$ & $6.7 \pm 2.1$ & $13.7 \pm 2.6$ & $0.5 \pm 0.2$ & $4.3 \pm 2.1$ & $1.9 \pm 1.0$ & $0.44 \pm 0.05$ & $0.4 \pm 0.5$ & $3.7 \pm 1.7$ & $0.2 \pm 0.1$ & $1.4 \pm 0.9$ \\
\hline Sep & 5 & $52 \pm 18$ & $0.13 \pm 0.06$ & $12.9 \pm 3.9$ & $15.3 \pm 2.2$ & $0.9 \pm 0.4$ & $6.9 \pm 2.6$ & $4.8 \pm 2.1$ & $0.68 \pm 0.11$ & $0.1 \pm 0.1$ & $5.0 \pm 1.1$ & $0.5 \pm 0.3$ & $1.2 \pm 0.7$ \\
\hline Oct & 6 & $78 \pm 47$ & $0.10 \pm 0.03$ & $20.0 \pm 7.8$ & $14.2 \pm 3.4$ & $1.5 \pm 0.8$ & $12.2 \pm 6.3$ & $8.4 \pm 4.8$ & $0.67 \pm 0.13$ & $0.9 \pm 1.2$ & $8.5 \pm 4.5$ & $0.9 \pm 0.6$ & $2.2 \pm 1.7$ \\
\hline Nov & 5 & $47 \pm 9$ & $0.10 \pm 0.04$ & $14.8 \pm 4.2$ & $12.3 \pm 3.7$ & $1.3 \pm 0.6$ & $9.1 \pm 4.3$ & $5.2 \pm 2.2$ & $0.61 \pm 0.19$ & $0.4 \pm 0.2$ & $4.8 \pm 3.1$ & $0.4 \pm 0.2$ & $1.0 \pm 0.1$ \\
\hline Dec & 6 & $48 \pm 20$ & $0.08 \pm 0.04$ & $19.7 \pm 3.8$ & $12.6 \pm 2.6$ & $1.7 \pm 0.7$ & $12.3 \pm 6.3$ & $6.7 \pm 2.8$ & $0.57 \pm 0.11$ & $0.5 \pm 0.6$ & $4.3 \pm 2.8$ & $0.5 \pm 0.2$ & $0.9 \pm 0.4$ \\
\hline
\end{tabular}

* AOD: average values (@ $500 \mathrm{~nm}$ ) for the respective months of the years 2002, 06, 07 and 08;

$b_{\mathrm{abs}}$ and $\sigma_{\mathrm{abs}}$ data are given at $678 \mathrm{~nm}$ wavelength.

$39.3 \%$ of the TSP) and 0.14 to $7.6 \mu \mathrm{gC} \mathrm{m}^{-3}$ (0.1 to $7.6 \%$ of the TSP), respectively (Figs. 3d, e). The monthly average mass concentrations of TSP, OC, EC, WSOC and selected inorganic aerosols are presented in Table 1.

A characteristics feature of TSP relates to the higher concentrations of carbonaceous aerosols during wintertime (December-March) resulting from regional biomass burning emissions. The mass concentrations of $\mathrm{OC}$ and $\mathrm{EC}$ exhibit a large seasonal and inter-annual variability during the sampling period. The lower concentrations of OC and $\mathrm{EC}$ are typical of the monsoon (due to efficient wash-out of aerosols) and premonsoon/summer months (due to the lower biomass burning emission); whereas relatively high concentrations are observed for the samples collected during post-monsoon and winter months (Figs. 3d, e). Carrico et al. (2003) have reported a similar seasonal variability for OC 
Table 2. Measured carbonaceous species and optical parameters (this study) and their inter-comparison with the reported data in the literature. Numbers in parenthesis represent median values.

\begin{tabular}{|c|c|c|c|c|c|c|c|c|c|}
\hline Sampling sites & Elevation & Sampling period & $\mathrm{OC}$ & $\mathrm{EC}$ & $\mathrm{OC} / \mathrm{EC}$ & $\mathrm{b}_{\mathrm{abs}}$ & $\sigma_{\text {abs }}$ & $\mathrm{AOD}$ & Reference \\
\hline & $(\mathrm{km})$ & & $\mu \mathrm{g} \mathrm{m}^{-3}$ & $\mu \mathrm{g} \mathrm{m}^{-3}$ & & $\mathrm{Mm}^{-1}$ & $\mathrm{~m}^{2} \mathrm{~g}^{-1}$ & & \\
\hline Manora Peak & 1.95 & Winter & $10.3 \pm 5.2(9.6)$ & $1.8 \pm 1.4(1.8)$ & $6.3 \pm 2.2(6.2)$ & $17.0 \pm 7.0(16.8)$ & $10.9 \pm 3.5(10.4)$ & $0.11 \pm 0.09(0.08)^{*}$ & Present study \\
\hline Manora Peak & 1.95 & Premonsoon & $6.1 \pm 4.1(4.4)$ & $0.9 \pm 0.6(0.8)$ & $7.4 \pm 3.1(6.3)$ & $11.3 \pm 5.8(10.5)$ & $12.1 \pm 2.5(12.9)$ & $0.29 \pm 0.09(0.31)^{*}$ & Present study \\
\hline Manora Peak & 1.95 & Monsoon & $4.5 \pm 2.6(4.2)$ & $0.5 \pm 0.3(0.5)$ & $9.2 \pm 5.5(8.1)$ & $7.4 \pm 4.6(7.5)$ & $13.5 \pm 3.0(14.0)$ & $0.09 \pm 0.09(0.09)^{*}$ & Present study \\
\hline Manora Peak & 1.95 & Post-monsoon & $10.8 \pm 5.5(10.5)$ & $1.4 \pm 0.7(1.2)$ & $7.5 \pm 1.3(7.2)$ & $17.6 \pm 13.3(15.5)$ & $13.3 \pm 3.5(14.8)$ & $0.08 \pm 0.02(0.10)^{*}$ & Present study \\
\hline Manora Peak & 1.95 & Feb 2005-Jul 2008 & $8.2 \pm 5.2(7.1)$ & $1.3 \pm 1.2(1.0)$ & $7.3 \pm 3.4(6.5)$ & $13.9 \pm 7.4(13.8)$ & $12.3 \pm 2.9(12.2)$ & $0.16 \pm 0.11(0.14)^{*}$ & Present study \\
\hline Manora Peak & 1.95 & Dec-2004 & $4.8 \pm 1.1(5.0)$ & $0.9 \pm 0.3(0.9)$ & $6.0 \pm 1.9$ & $12.9 \pm 4.6$ & $14.5 \pm 1.1$ & & Rengarajan et al. (2007) \\
\hline Mt Abu & 1.70 & May 2005-Feb 2006 & $3.7 \pm 2.4$ & $0.5 \pm 0.5$ & $6.1 \pm 2.0$ & $5.8 \pm 4.3$ & $9.8 \pm 2.1$ & & Ram and Sarin (2009) \\
\hline NCO-P & 5.079 & Winter 2006 & & & & & & $0.04^{* *}$ & Gobbi et al. (2010) \\
\hline NCO-P & 5.079 & May-Sep 2006 & & & & & & $0.14^{* *}$ & Gobbi et al. (2010) \\
\hline NCO-P & 5.079 & May-Sep 2006 & 2.0 & 0.2 & $5.6-9.1$ & & & & Decesari et al. (2010) \\
\hline \multirow[t]{2}{*}{ NCO-P } & 5.079 & May-Sep 2006 & & & & $1.1 \pm 2.1^{* * * *}$ & & & Marcq et al. (2010) \\
\hline & 2.15 & Oct 99-Jan 2000 & 6.3 & 1.0 & 6.3 & & & & Carrico et al. (2003) \\
\hline Nagarkot, Nepal & & Feb-May & 14.4 & 0.9 & 15.3 & & & & \\
\hline \multirow[t]{3}{*}{ Langtang, Nepal } & 3.92 & Jun-Sep & 2.0 & 0.3 & 6.7 & & & & \\
\hline & & Oct 99-Jan 2000 & 1.8 & 0.5 & 3.5 & & & & Carrico et al. (2003) \\
\hline & & Feb-May & 3.4 & 0.3 & 11.5 & & & & \\
\hline \multirow[t]{2}{*}{ Mt. Kanobili, Georgia } & 2.0 & Jun-Sep & 0.8 & 0.1 & 7.9 & & & & \\
\hline & & Jul & 2.5 & 1.1 & 2.3 & & & & Dzubay et al. (1984) \\
\hline Nylsvley Natural Reserve, So & 1.1 & May & 14.1 & 0.9 & 16.6 & & & & Puxbaum et al. (2000) \\
\hline \multirow[t]{2}{*}{ Mt. Sonnblick, Austria } & 3.1 & Jul & 53.7 & 5 & 10.7 & & & & Hitzenberger et al. (1999) \\
\hline & & Sep & 16.2 & 3.8 & 4.3 & & & & Hitzenberger et al. (1999) \\
\hline Mutztagh At & & Dec 2003-Feb 2005 & 0.48 & 0.055 & 8.7 & & & & Cao et al. (2009) \\
\hline Daihai, China & & & 19.9 & 3.1 & 6.4 & & & & Han et al. (2008) \\
\hline
\end{tabular}

* Average of AOD data (@ 500 nm) for the years 2002 and 2006-2008.

Seasons are defined as: winter (December-March), premonsoon/summer (April-June), monsoon (July-September), post-monsoon (October-November);

** Median values (@500 nm);

*** annual average (@670 nm).

and EC concentrations at high-altitude locations (Nagarkot and Langtang). Adhikary et al. (2007) had also reported elevated concentrations of OC and EC after post-monsoon and dry months (up to May) at Kathmandu in the Himalaya. In this study, the mass concentrations of OC and EC (9.6 and $1.5 \mu \mathrm{gC} \mathrm{m}{ }^{-3}$, respectively) during April 2005 are significantly lower than those (51.0 and $4.0 \mu \mathrm{gC} \mathrm{m}^{-3}$, respectively) reported by Adhikary et al. (2007) for the same time-period. The highest OC concentration $\left(22.3 \mu \mathrm{gC} \mathrm{m}^{-3}\right)$ was observed on 26 October 2005 (DOY 299; Fig. 3d). The EC concentration was generally less than $4 \mu \mathrm{gC} \mathrm{m}^{-3}$, however, on some days was as high as $7.6 \mu \mathrm{gC} \mathrm{m}^{-3}$ (e.g. 4 March 2008; DOY 64; Fig. 3e). An inter-comparison of mass concentrations of EC and OC at Manora Peak and some of the high-altitude sites in the world is presented in Table 2.

Total carbonaceous aerosols (TCA) is estimated as the sum of organic matter $(\mathrm{OM})$ and $\mathrm{EC}($ i.e. $\mathrm{TCA}=1.8 \times \mathrm{OC}+\mathrm{EC})$. A value of 1.8 has been used for converting the measured OC to organic matter (Cozic et al., 2008). The conversion factor used in this study is relatively higher than that for urban locations (Rengarajan et al., 2007; Turpin and Lim, 2001) because of the aging of aerosols during transport to the high-altitude and the presence of oxygenated organic compounds (Zhang et al., 2007). This is further supported by relatively high WSOC/OC ratios at Manora Peak compared to those at urban locations in the Indo-Gangetic Plain (Ram and Sarin, 2010). The seasonal variability in the mass concentrations of TSP and carbonaceous species is significantly pronounced during the study period. The chemical composition of aerosols, at Manora Peak, for the four seasons is presented in Fig. 4. The TSP mass is the highest during premonsoon/summer followed by winter and post-monsoon whereas the lowest TSP was observed during monsoon season. The aerosol chemical composition is similar during winter and post-monsoon seasons, with relatively high contribution of carbonaceous aerosols ( $\sim 30-35 \%$ of the TSP). On the contrary, fractional contribution of OC (as organic matter) and EC are lower in the premonsoon and monsoon (Fig. 4). Aerosol composition during premonsoon is dominated by mineral aerosols ( $~ 65 \%$ of the TSP mass; Fig. 4 ). It should be noted that mineral dust is estimated by taking the difference of measured concentration of OM, EC and WSIS (sum of the concentrations of cations and anions) in aerosols. The analytical uncertainties in measurements of carbonaceous species and the use of conversion factor can have an error of the order of $20 \%$. Nevertheless, our inference is based on increase in the mass concentration of carbonate carbon and $\mathrm{Ca}^{2+}$ (used as an index of mineral dust) during the summer (Table 1 ) and dust events (Table 3 ). The use of conversion factor to infer OM can only change the fraction of mineral dust. Thus, the conspicuous change in the aerosol composition can be explained in terms of the varying source strength of carbonaceous aerosols and mineral dust, and meteorological conditions (rainfall and wind pattern).

\section{Chemical characteristics of aerosols during dust storms}

The chemical characteristics of mineral aerosols indicate dominant contribution from carbonate-rich minerals over semi-arid urban and high-altitude sites in westernIndia (Kumar and Sarin, 2009; Rastogi and Sarin, 2009). 
Table 3. The chemical composition and optical parameters in ambient aerosols at Manora Peak during normal days and Dust events in the premonsoon season (April-June).

\begin{tabular}{lccccccccc}
\hline Aerosol-types & TSP & EC & OC & WSOC & $\mathrm{CC}^{*}$ & $\mathrm{Ca}^{2+}$ & $\mathrm{NO}_{3}^{-}$ & $\mathrm{SO}_{4}^{2-}$ & $\mathrm{NH}_{4}^{+}$ \\
\hline & & \multicolumn{7}{c}{$\mu \mathrm{g} \mathrm{m}{ }^{-3}$} \\
Normal days & $29.0 \pm 8.4$ & $0.6 \pm 0.3$ & $3.6 \pm 2.1$ & $2.0 \pm 0.5$ & $0.3 \pm 0.3$ & $0.5 \pm 0.2$ & $0.2 \pm 0.2$ & $4.7 \pm 4.5$ & $0.5 \pm 0.5$ \\
Dust events & $159.0 \pm 55.6$ & $1.5 \pm 0.6$ & $10.5 \pm 0.6$ & $5.3 \pm 1.9$ & $1.8 \pm 1.1$ & $2.7 \pm 0.7$ & $1.9 \pm 0.9$ & $5.0 \pm 2.0$ & $0.3 \pm 0.2$ \\
\hline
\end{tabular}

* carbonate carbon

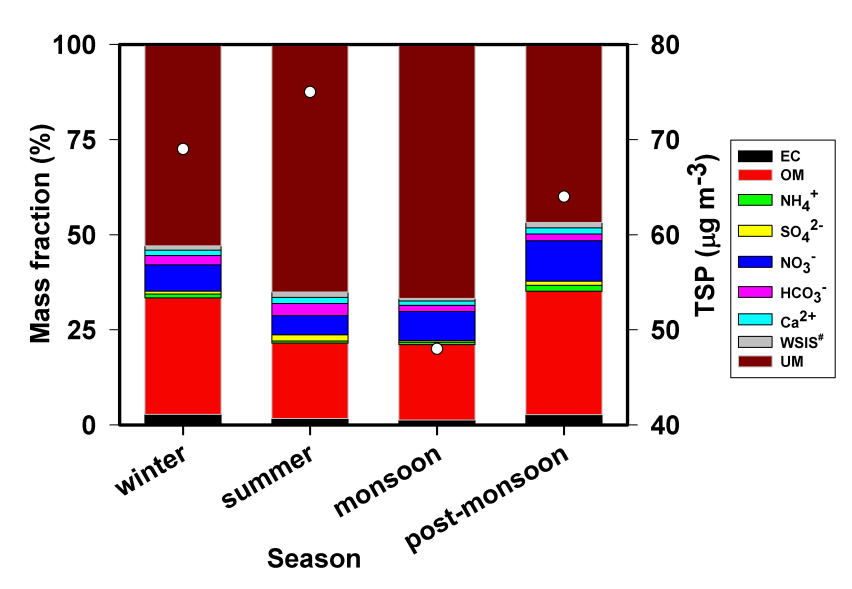

Fig. 4. Chemical composition of aerosols collected at Manora Peak for the four seasons. OM refers to the organic matter $(=1.8 \times \mathrm{OC})$, WSIS ${ }^{\#}$ (sum of $\mathrm{Cl}^{-}, \mathrm{K}^{+}, \mathrm{Mg}^{2+}$ and $\mathrm{Na}^{+}$) and unaccounted mass (UM) is defined as TSP - OM - EC - WSIS ${ }^{\#}$. The open circles represent the TSP mass (y-axis).

Mineral aerosols are primarily composed of calcium sulphate (or Gypsum), calcite $\left(\mathrm{CaCO}_{3}\right), \mathrm{MgCO}_{3}$, dolomite $\left[\mathrm{CaMg}\left(\mathrm{CO}_{3}\right)_{2}\right]$ and alumino-slilicates. For example, Cong et al. (2008) have reported that aerosol samples, collected from Mt. Qomolangma (Everest) during May-June 2005, were mainly composed of alumino-silicates/silica (55\%), calcium sulphate (16\%), $\mathrm{Ca} / \mathrm{Mg}$ carbonate $(2 \%)$ and soot $(8 \%)$. The reactive fractions of mineral dust such as $\mathrm{CaCO}_{3}, \mathrm{MgCO}_{3}$ and $\mathrm{CaMg}\left(\mathrm{CO}_{3}\right)_{2}$, can be replaced by the atmospheric acidic species such as $\mathrm{H}_{2} \mathrm{SO}_{4}$ and $\mathrm{HNO}_{3}$ during the transport through the heterogeneous chemical processes occurring on mineral surfaces (Favez et al., 2008). This changes the morphology, phase of the dust (calcite) particles, optical properties and the ability to act as cloud condensation nuclei (CCN) (Geng et al., 2009).

The desert-regions of the middle-East and the Thar Desert (in western India) are major sources of dust over Indian region. The frequency of dust storm over northern India is 6 to 8 per year (Chinnam et al., 2006; Dey et al., 2004; Hegde et al., 2007). The highest TSP concentration of $272 \mu \mathrm{g} \mathrm{m}^{-3}$ that occurred on 11th June 2006 (DOY: 162; Fig. 3a), was associated with a dust storm (see Fig. 1) (Hegde et al., 2007).
The concentration of carbonate carbon (CC) during storm events shows an order of magnitude increase (compared to the average CC concentration) and co-varies with the TSP mass (Fig. 3b). Furthermore, concentrations of water-soluble $\mathrm{Ca}^{2+}$, a tracer of mineral dust, also exhibit an increasing trend (similar to TSP) (Fig. 3c). Thus, the chemical composition during dust storm events is marked by a relative increase in the $\mathrm{CC}$ and $\mathrm{Ca}^{2+}$ concentrations (Figs. 3b, c and Table 3). The mass concentrations of carbonaceous species (OC, EC) and their fractional contribution show a decrease during dust storm events (Figs. 3d and e). The concentration of $\mathrm{K}^{+}$, used as an indicator of biomass burning emission, is also relatively low during storm events (Fig. 3g). However, $\mathrm{NO}_{3}^{-}$concentrations show a significant increase during storm period (Fig. 3h), suggesting that $\mathrm{NO}_{3}^{-}$is associated with mineral dust through heterogeneous uptake of reactive gaseous nitrogen species on mineral surfaces (Geng et al., 2009). In contrast, the concentration of $\mathrm{SO}_{4}^{2-}$ does not show noticeable increase during dust storm events (Fig. 3i). Furthermore, the fractional contribution of water-soluble ionic species decreased to $7 \%$ on 11 June 2006. It is noteworthy that not only the contribution of WSIS decreased during dust events; the contribution of TCA was reduced to $6.6 \%$ on 11 June 2006. These results suggest that the contribution from mineral aerosols can be as high as $\sim 85 \%$ during storm events. On average, TCA contributes $\sim 25 \%$ of the TSP during normal days. However, the fractional contribution of TCA increases to as high as $65 \%$ of the TSP for some days during winter and post-monsoon seasons. The aerosol chemical composition during dust storms and normal days in the premonsoon season is presented in Table 3.

\section{Source of carbonaceous aerosols and OC/EC ratios}

The OC/EC ratios in aerosol samples varied from 4.0 to 27.2 during the sampling period (Av: 7.7 $\pm 3.4,1 \sigma$ for $n=86$,). The relatively high OC/EC ratios at Manora Peak suggest the dominance of scattering OC over the absorbing EC. The elevated OC/EC ratios also suggest that these species are derived from a primary emission sources (such as biomass burning sources in the Indo-Gangetic Plain) and contribution of secondary organic aerosols (SOA). Biomass burning 

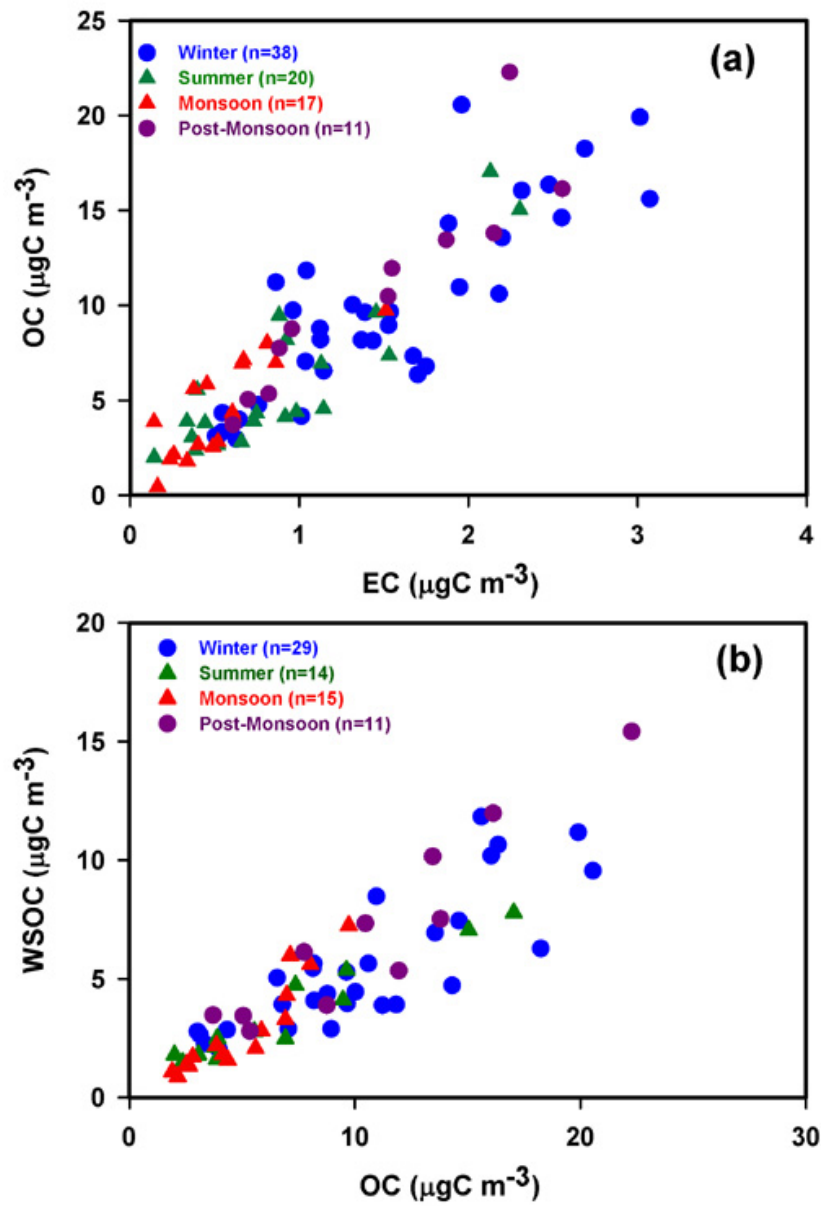

Fig. 5. Scatter plots between (a) OC and EC and (b) WSOC and OC.

emissions produce relatively high fraction of OC compared to EC and thus, results in an enriched OC/EC ratios (Andreae and Merlet, 2001). In contrast, vehicular and industrial emissions produce relatively lower OC/EC ratios (Saarikoski et al., 2008). However, the use of OC/EC ratios for the source apportionment need to be made with a great care as the measurements of OC and EC mass concentrations via thermal methods with similar measurement protocols can lead to different OC/EC ratios (Schauer et al., 2003).

There are no major anthropogenic and industrial activities located at Manora Peak. Earlier studies have suggested that the majority of carbonaceous aerosols over north India originate from biomass (used for cooking and residential heating purposes) and agriculture crop-waste burning emissions (Rengarajan et al., 2007; Venkataraman et al., 2005). Based on a robust radiocarbon $\left({ }^{14} \mathrm{C}\right)$ analysis in ambient aerosols, Gustafsson et al. (2009) have concluded that biomass combustion contributes to two-thirds of the total organic carbon and $\sim 50 \%$ for elemental carbon over India. A significant linear relationship between OC and EC $\left(R^{2}=0.83, n=86\right.$,
Fig. 5a) suggests that their mass fraction in TCA and/or the emission sources of carbonaceous species have not significantly changed during the sampling period. Based on $\mathrm{K}^{+} / \mathrm{OC}$ ratios (range: 0.02-0.14; average: $0.06 \pm 0.02$ ) in aerosol samples collected over the IGP, Ram and Sarin $(2010,2011)$ have inferred that biomass burning of agricultural waste and wood-fuel is a major source of carbonaceous aerosols. The $\mathrm{K}^{+} / \mathrm{OC}$ ratios (range: $0.01-0.09$; average: $0.05 \pm 0.02$ ) at Manora Peak are similar to the ratios obtained in the IGP. The biomass burning emission strength increases during wintertime (December-February) in the IGP when ambient temperature is relatively lower. This is further supported by a relative increase in $\mathrm{K}^{+}$concentrations during wintertime $\left(0.6 \mu \mathrm{g} \mathrm{m}^{-3}\right)$ compared to summer months $\left(0.3 \mu \mathrm{g} \mathrm{m}^{-3}\right)$ at Manora Peak.

As stated earlier, high OC/EC ratios at Manora Peak could also result from the enhanced SOA formation. However, this would reflect in the seasonal variability in OC/EC ratios as SOA formation exhibit a seasonal pattern (Castro et al., 1999; Chang and Lee, 2007). These studies have suggested relatively higher SOA formation during premonsoon (due to higher photochemical activity) compared to that in winter months. The seasonally averaged (median) OC/EC ratios during winter, premonsoon and post-monsoon are $6.3 \pm 2.2$ (6.7), $7.4 \pm 3.1$ (8.0) and $7.5 \pm 1.3$ (7.2), respectively. Although, seasonally averaged OC/EC ratios are similar and statistically indistinguishable; median values of OC/EC ratio for pre- and post-monsoon seasons are relatively higher compared to that during winter season. The estimated secondary organic carbon (SOC), using the EC tracer method (Castro et al., 1999; Ram et al., 2008), exhibit a seasonal pattern and average SOC contribute to $\sim 30,48$ and $20 \%$ (of OC) during winter, pre- and post-monsoon seasons, respectively. Thus, it can be inferred that higher OC/EC ratios at Manora Peak are mainly derived from the transport of biomass burning emissions in the IGP and western parts of India with contribution from secondary organic aerosols.

\section{WSOC mass concentration and WSOC/OC ratios}

The mass concentration of WSOC at Manora Peak varied from 0.9 to $15.4 \mu \mathrm{gC} \mathrm{m}^{-3}$ during the study period (Fig. 3f). The WSOC concentration exhibit a significant positive correlation with $\mathrm{OC}$ and all data points fall on a line with a slope of $0.55\left(R^{2}=0.79, n=69, p<0.05\right.$, Fig. 5b). However, some of the data points plot differently with respect to WSOC/OC ratios for the same time-period. The relatively low WSOC/OC ratios $(0.35)$ in the aerosol samples collected during the winter indicate poor aging, dominant contribution from primary emission sources and transport from the Indo-Gangetic Plain. Such an inference is further corroborated by lower WSOC/OC ratios observed at urban locations (range: 0.32 to 0.40 ) in the IGP during the wintertime (Ram and Sarin, 2010). Furthermore, a moderate correlation 
between WSOC and $\mathrm{SO}_{4}^{2-}$ during the wintertime $\left(R^{2}=0.57\right.$, $n=29$, figure not shown) suggest their transport from the Indo-Gangetic Plain. Recently, Decesari et al. (2010) have suggested that the Valley breeze circulation has a strong impact on the aerosol composition at NCO-P site in the Himalaya and could be a possible mechanism for the transport of aerosols from the IGP. The water-insoluble OC (WIOC; defined as the difference between OC and WSOC) is mainly derived from primary emissions such as biomass burning and vehicular exhausts (Favez et al., 2008). The WIOC concentration shows a linear relationship with thermal EC concentrations $\left(R^{2}=0.48, n=69\right.$, figure not shown) and the slope (2.6) is similar to WIOC/EC ratios in the IGP for primary emission sources (Ram and Sarin, 2010). The median WIOC/EC ratios at Manora Peak, during the four seasons, are 3.0 (winter), 3.8 (summer/premonsoon), 3.9 (monsoon) and 2.6 (post-monsoon). A close similarity in the WIOC/EC ratios at Manora Peak with those in the IGP (Ram and Sarin, 2010) further support the advective transport of primary emitted aerosols from the Indo-Gangetic Plain.

The average WSOC/OC ratio at Manora Peak $(0.55 \pm 0.15$; median 0.53$)$ is lower than that reported from the Himalayan Nepal Climate Observatory-Pyramid $(0.65 \pm 0.15)$ situated at an altitude of $5079 \mathrm{~m}$ a.s.l. (Decesari et al., 2010). The WSOC mass concentrations and WSOC/OC ratios can be used as an indicator for the secondary organic aerosol (SOA) formation because most of the SOA are soluble in water (Kondo et al., 2007; Weber et al., 2007). The WSOC/OC ratios do not exhibit any seasonal variability during the sampling period. However, WSOC/EC ratios during premonsoon are relatively higher compared to that during winter season. Therefore, an increase in WSOC/OC (or WSOC/EC) ratios suggests the aging, chemically processed aerosols and/or possible contribution from the SOA (Zhang et al., 2007).

\section{Optical properties}

\subsection{Aerosol optical depth (AOD)}

Dust storm does not only affect the chemical composition, they also change physical and optical properties (e.g. AOD and fine-mode aerosol fraction, FMAF) of aerosols (Jethva et al., 2005). The aerosol size-distribution during storm days shows an increase in coarse-mode particles (Hegde et al., 2007) and a decrease in the FMAF values (Jethva et al., 2005). During the dust storm event in June 2006, Hegde et al. (2007) have reported that number concentration of coarsemode particles and aerosol optical depth values increased by a factor of five compared to the respective monthly mean values. A compilation of AOD values, reported in the literature (from 2002 onward) and those measured during 2006-2008 at Manora Peak, are presented in Fig. 6. The monthly averaged AOD values and TSP mass concentrations, along with measured chemical parameters for the sampling period, are

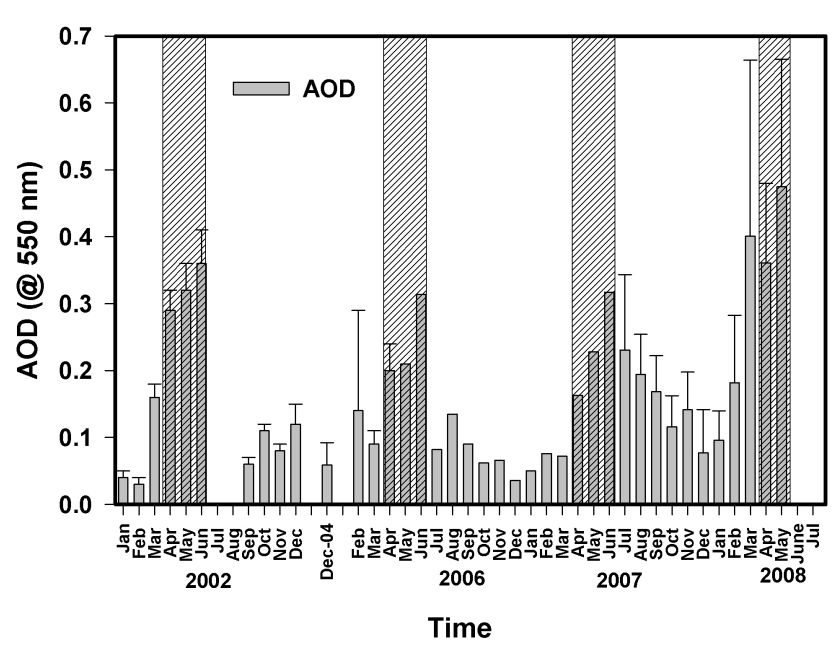

Fig. 6. The monthly mean aerosol optical depth (AOD @ 550 nm) at Manora Peak. The AOD data for the years 2002 and Dec 2004 are taken from Sagar et al. (2004) and Pant et al. (2006), respectively. The vertical strips indicate the high AOD representing premonsoon season (April-June) of the respective years.

summarized in Table 1. It is noticeable that AOD values at Manora Peak show a significant increase (factor of two to six) during premonsoon compared to those during winter months (Fig. 6; Table 1). Based on a one-year measurements of AOD with a sunphotometer at the Himalayan Nepal Climate Observatory-Pyramid, Gobbi et al. (2010) have shown that AOD values show maximum during May-September and minimum in the winter months. The higher AOD values during premonsoon are attributed to the increase in abundance of mineral aerosols whereas lower AOD values during monsoon are attributed to an efficient wash-out by rain.

\section{Absorption coefficient $\left(b_{\text {abs }}\right)$}

The absorption coefficient $\left(b_{\text {abs }}\right)$ and mass absorption efficiency of EC $\left(\sigma_{\mathrm{abs}}\right)$ were simultaneously assessed using the thermo-optical EC-OC analyzer and all the values presented in this study are given at $678 \mathrm{~nm}$ (Tables 1 and 2). The measured $b_{\mathrm{abs}}$ values ranged from 0.9 to $33.9 \mathrm{Mm}^{-1}$ $\left(1 \mathrm{Mm}^{-1}=10^{-6} \mathrm{~m}^{-1}\right)$ and exhibit a large temporal and interannual variability during the sampling period (Figs. 7 and 8a). The higher $b_{\text {abs }}$ values were observed for the aerosol samples collected during winter and post-monsoon months whereas lower values were associated with premonsoon and monsoon months. The monthly average EC mass concentration, $b_{\mathrm{abs}}$ and $\sigma_{\mathrm{abs}}$ values are shown in Fig. 8b. Generally, absorption coefficient decreases April onward and the minimum was observed in July (monsoon month) and then it continues to increase until end of the March. The trend of $b_{\mathrm{abs}}$ values at Manora Peak closely follows EC concentration trend (Fig. 8b) suggesting EC as a major absorbing species. Recently, Hyvärinen et al. (2009) have 


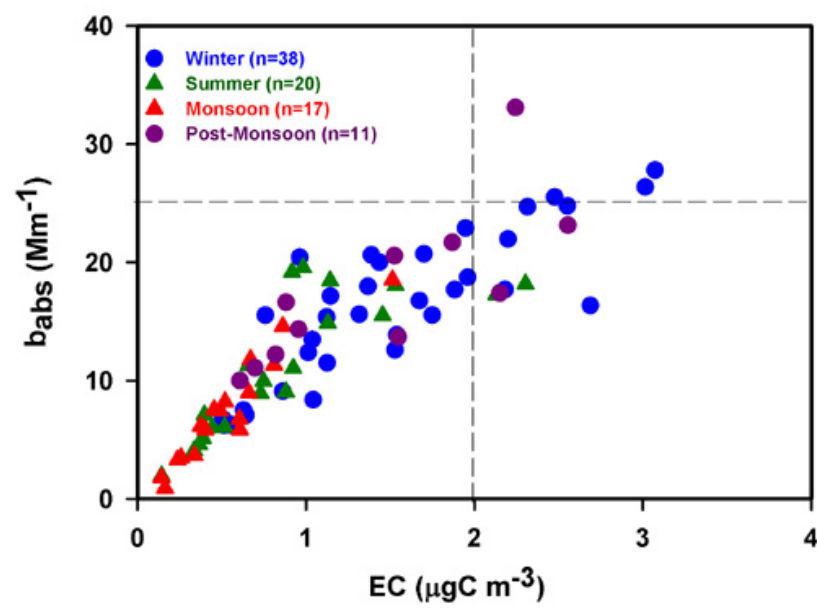

Fig. 7. The scatter plot between $b_{\mathrm{abs}}$ and EC concentration exhibit significant correlation up to $25 \mathrm{Mm}^{-1}$ (shown by horizontal dashed line) and $2.0 \mu \mathrm{gC} \mathrm{m}^{-3}$ (shown by vertical dashed line). The linearity ceases at higher EC concentrations and high $b_{\text {abs }}$ values.

reported that $b_{\text {abs }}$ values measured using an Aethalometer varies from 4.5 to $23.2 \mathrm{Mm}^{-1}$ during September 2005September 2007 at Mukteshwar, a high-altitude site in northern India located nearby Manora Peak. The BC mass concentrations, based on Aethalometer measurement, also exhibit a large spatio-temporal variability over Indian regions (Beegum et al., 2009). If BC mass concentrations are converted to $b_{\mathrm{abs}}$, one can find that $b_{\mathrm{abs}}$ values at Manora Peak are an order of magnitude lower compared to those in the Indo-Gangetic Plain (Ram and Sarin, 2009). Furthermore, the annual average $b_{\text {abs }}$ values at Manora Peak are factor of two higher than those at Mt Abu, another high-altitude site in western India (Ram and Sarin, 2009). A comparison of EC mass concentration, absorption coefficient $\left(b_{\mathrm{abs}}\right)$, mass absorption efficiency $\left(\sigma_{\mathrm{abs}}\right)$ and AOD values in the Himalayas and other high-altitude sites are presented in Table 2.

\section{Mass absorption efficiency of EC $\left(\sigma_{\mathrm{abs}}\right)$}

The $\sigma_{\text {abs }}$ values at Manora Peak ranges from 4.4 to $21.2 \mathrm{~m}^{2} \mathrm{~g}^{-1}$ for the entire sampling period (February 2005July 2008). Despite of a large temporal and sample-tosample variability in $\sigma_{\mathrm{abs}}$ values, measured $b_{\mathrm{abs}}$ values and thermal EC (in unit of $\mu \mathrm{gC} \mathrm{m}^{-3}$ ) show a good correlation for the data with $\mathrm{EC}<2.0 \mu \mathrm{gC} \mathrm{m} \mathrm{m}^{-3}$ and/or $b_{\text {abs }}<25 \mathrm{Mm}^{-1}$ $\left(R^{2}=0.72, n=73\right.$, Fig. 7) and the slope of the best-fit line provides a value of $12.2 \mathrm{~m}^{2} \mathrm{~g}^{-1}$. However, the linearity ceases for the data with $\mathrm{EC}>2.0 \mu \mathrm{gC} \mathrm{m}{ }^{-3}$ and/or $b_{a b s}>25 \mathrm{Mm}^{-1}$. Most of these data points represent collection of aerosol samples during wintertime (Fig. 7). The samples collected during wintertime have relatively lower $\sigma_{\mathrm{abs}}$ values compared to those for other seasons (Fig. 8b and Table 1).

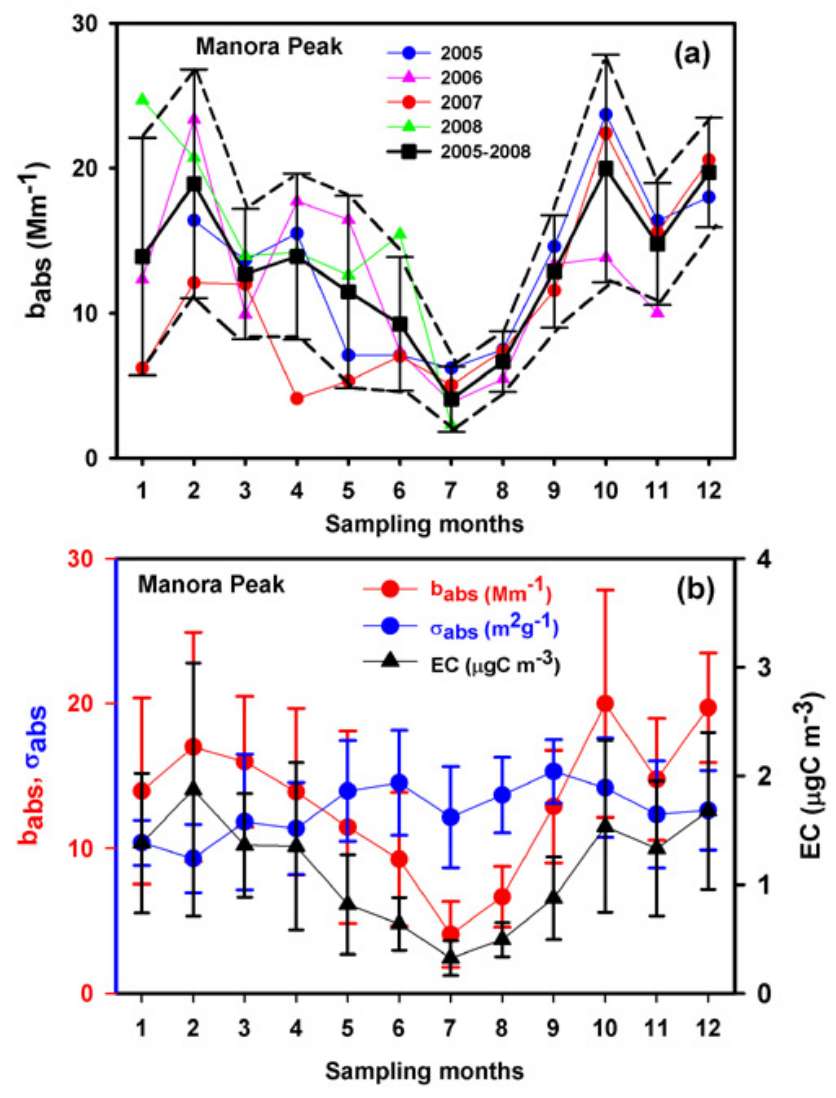

Fig. 8. (a) The temporal variability of average $b_{\text {abs }}$ for the years 2005, 2006, 2007 and 2008. Data points shown by filled squares refer to monthly average values of $b_{\text {abs }}$ for four years (b) The monthly average values of $b_{\mathrm{abs}}, \sigma_{\mathrm{abs}}$, and $\mathrm{EC}$ mass concentrations.

The variability in $\sigma_{\mathrm{abs}}$ values, reported in the literature, has been explained in terms of the sources, chemical composition, measurement protocols, aerosol aging and the mixing state of aerosols (Liousse et al., 1993; Ram and Sarin, 2009; Sharma et al., 2002). For example, Liousse et al. (1993) have reported that $\sigma_{\text {abs }}$ values varied from 2 to $25 \mathrm{~m}^{2} \mathrm{~g}^{-1}$ for aerosol samples derived from different emission sources. Sharma et al. (2002) have explained the variability in $\sigma_{\mathrm{abs}}$ values (6.4 to $20.1 \mathrm{~m}^{2} \mathrm{~g}^{-1}$ ) in terms of the sources and atmospheric processing of aerosols reaching at rural, urban and sub-urban sampling sites in Canada. Cozic et al. (2008) have reported that $\sigma_{\text {abs }}$ values showed a seasonal variability with an average values of $7.6 \pm 0.2 \mathrm{~m}^{2} \mathrm{~g}^{-1}$ (winter) and $11.1 \pm 0.2 \mathrm{~m}^{2} \mathrm{~g}^{-1}$ (summer) and suggested that higher $\sigma_{\mathrm{abs}}$ values in summer probably resulted because of greater coating of $\mathrm{BC}$ due to the photochemical activity. The mixing state of aerosols (external or internal) could be a probable reason for observed seasonal variability in the mass absorption efficiency at Manora Peak (Table 1, Fig. 8b). The internal and/or external mixing depends on aerosol chemical composition (mainly $\mathrm{SO}_{4}^{2-}, \mathrm{NO}_{3}^{-}$and WSOC), hygroscopicity and chemical processing in the atmosphere. In the presence of 
photochemistry, secondary aerosol formation and their coating can lead to an increase in the absorption signal for the same amount of absorbing EC (Bond et al., 2006; Moffet and Prather, 2009). The aerosol particles collected at Manora Peak (during winter) are relatively drier, located near the source regions (i.e. freshly emitted) and may exist as an external mixture of aerosols and thus, probably have lower $\sigma_{\mathrm{abs}}$ values. On the other hand, aerosol particles collected during premonsoon are aged and chemically processed during the transport and may exist as an internally mixed particle, thus resulting in higher $\sigma_{\text {abs }}$ values. However, the reasons for the variability in mass absorption efficiency of EC need to be further investigated.

The $\sigma_{\text {abs }}$ values, obtained in this study, are higher than those reported during the PRIDE-PRD 2004 experiment, e.g. $7.7 \mathrm{~m}^{2} \mathrm{~g}^{-1}$ (Andreae et al., 2008); $7.2 \pm 1.0$ and $9.3 \pm 1.4 \mathrm{~m}^{2} \mathrm{~g}^{-1}$ for $\mathrm{PM}_{1}$ and $\mathrm{PM}_{10}$ aerosols (Cheng et al., 2008). Bond and Bergstrom (2006) have suggested a value of $7.5 \pm 1.2 \mathrm{~m}^{2} \mathrm{~g}^{-1}$ for the $\sigma_{\text {abs }}$ at $550 \mathrm{~nm}$ for freshly emitted soot particles. However, if we assume an enhancement of $50 \%$ in the absorption for coated and aged aerosols (Bond et al., 2006); the observed $\sigma_{\text {abs }}$ value $\left(12.2 \pm 2.3 \mathrm{~m}^{2} \mathrm{~g}^{-1}\right)$ is in the similar range as suggested in the literature. The average $\sigma_{\text {abs }}$ value at Manora Peak is relatively higher than the commonly cited value of $10.0 \mathrm{~m}^{2} \mathrm{~g}^{-1}$ and that used in the Particle Soot Absorption Photometer (PSAP) for the determination of BC mass concentrations (Sharma et al., 2002). In a recent study, Miyazaki et al. (2008) have reported $\sigma_{\text {abs }}$ as $9.8 \pm 0.1 \mathrm{~m}^{2} \mathrm{~g}^{-1}$ for a suburban site in Thailand based on a newly designed Continuous Soot Monitoring System (COSMOS) for the measurement of BC. Based on Aerosol Robotic Network (AERONET) retrievals, Schuster et al. (2005) have derived an average values of 10.5 and $10.0 \mathrm{~m}^{2} \mathrm{~g}^{-1}$ for Asian continental aerosols for the years 2000 and 2001. Dey and Tripathi (2006) have reported $\sigma_{\text {abs }}$ as $7.9 \pm 1.8,9.7 \pm 3.4$ and $12.7 \pm 2.9 \mathrm{~m}^{2} \mathrm{~g}^{-1}$ at an urban location (Kanpur) in northern India, for the years 2001, 2002 and 2003 respectively. The average $\sigma_{\text {abs }}$, obtained in this study, is similar to those reported for Asian aerosols derived based on the AERONET retrievals.

\section{Conclusions and implications}

A three-year study, carried out from a high-altitude site (Manora Peak) located in the foot-hills of central Himalaya, has provided important data set on the temporal variability in the ambient concentrations of EC, OC, WSOC and their transport from the source regions in the Indo-Gangetic Plain. In addition, optical properties and mass absorption efficiency of EC have been studied. The important findings are:

The mass concentration of organic carbon exhibit large temporal variability (range: 0.4 to $22.3 \mu \mathrm{gC} \mathrm{m}^{-3}$ ) and on average, it accounts for $\sim 15 \%$ of the TSP mass. The EC concentration and absorption coefficient $\left(b_{\mathrm{abs}}\right)$ varied by an order of magnitude; range: 0.1 to $7.6 \mu \mathrm{gC} \mathrm{m}^{-3}$ and 0.9 to $33.9 \mathrm{Mm}^{-1}$, respectively. The representative mass absorption efficiency of EC, at Manora Peak, is $12.2( \pm 2.3)$ $\mathrm{m}^{2} \mathrm{~g}^{-1}$. However, mass absorption efficiency of EC $\left(\sigma_{\mathrm{abs}}\right)$ shows relatively low values during winter season and high in summer (April-June) and post-monsoon (SeptemberNovember). The seasonal variability in $\sigma_{\text {abs }}$ is attributed to the aging, chemical processing and thus, changes in the mixing state of aerosols during the transport.

The monthly mean AOD varied from 0.03 to of 0.47 and exhibit maximum during the summer. The temporal variability in TSP mass is significantly pronounced during the sampling year of 2006 marked by dust storms. The relatively high TSP and AOD, during premonsoon, are attributed to the transport of mineral dust originating from desert regions in the middle-East and the Thar Desert in western India.

Another conspicuous feature of carbonaceous aerosols is reflected in the high OC/EC $(\mathrm{Av}=7.7 \pm 3.4)$ and WSOC/OC $(A v=0.55 \pm 0.15)$ at Manora Peak; suggesting enhanced contribution of secondary organic aerosols. These results are useful for the assessment of single scattering albedo (SSA) and aerosol radiative forcing on a regional scale.

Acknowledgements. The authors acknowledge the financial support received from the ISRO-Geosphere Biosphere Programme Office (Bangaluru, India). The constructive comments and suggestions provided by the two reviewers were very helpful in revising this manuscript.

Edited by: J. J. Schauer

\section{References}

Adhikary, B., Carmichael, G. R., Tang, Y., Leung, L. R., Qian, Y., Schauer, J. J., Stone, E. A., Ramanathan, V., and Ramana, M. V.: Characterization of the seasonal cycle of south Asian aerosols: A regional-scale modeling analysis, J. Geophys. Res., 112, D22S22, doi:10.1029/2006JD008143, 2007.

Andreae, M. O. and Merlet, P.: Emission of trace gases and aerosols from biomass burning, Global Biogeochem. Cy., 15, 955-966, 2001.

Andreae, M. O., Schmid, O., Yang, H., Chand, D., Yu, J. Z., Zeng, L.-M., and Zhang, Y.-H.: Optical properties and chemical composition of the atmospheric aerosol in urban Guangzhou, China, Atmos. Environ., 42, 6335-6350, 2008.

Beegum, I. N., Moorthy, K. K., Babu, S. S., Satheesh, S. K., Vinoj, V., Badarinath, K. V. S., Safai, P. D., Devara, P. C. S., Singh, S., Vinod, Dumka, U. C., and Pant, P.: Spatial distribution of aerosol black carbon over India during pre-monsoon season, Atmos. Environ., 43, 1071-1078, 2009.

Bonasoni, P., Laj, P., Marinoni, A., Sprenger, M., Angelini, F., Arduini, J., Bonafè, U., Calzolari, F., Colombo, T., Decesari, S., Di Biagio, C., di Sarra, A. G., Evangelisti, F., Duchi, R., Facchini, MC., Fuzzi, S., Gobbi, G. P., Maione, M., Panday, A., Roccato, F., Sellegri, K., Venzac, H., Verza, GP., Villani, P., Vuillermoz, E., and Cristofanelli, P.: Atmospheric Brown Clouds in the Himalayas: first two years of continuous observations at the Nepal 
Climate Observatory-Pyramid (5079 m), Atmos. Chem. Phys., 10, 7515-7531, doi:10.5194/acp-10-7515-2010, 2010.

Bond, T. C. and Bergstrom, R. W.: Light absorption by carbonaceous particles: An investigative review, Aerosol Sci. Technol., 40, 1-41, 2006.

Bond, T. C., Habib, G., and Bergstrom, R. W.: Limitations in the enhancement of visible light absorption due to mixing state, J. Geophys. Res., 111, D20211, doi:10.1029/2006JD007315, 2006.

Cachier, H., Bremond, M.-P., and Buat-Menard, P.: Determination of atmospheric soot carbon with a sample thermal method, Tellus, 41B, 379-390, 1989.

Carmichael, G. R., Adhikary, B., Kulkarni, S., DAllura, A., Tang, Y., Streets, D., Zhang, Q., Bond, T. C., Ramanathan, V., Jamroensan, A., and Marrapu, P.: Asian Aerosols: Current and Year 2030 Distributions and Implications to Human Health and Regional Climate Change, Environ. Sci. Technol., 43, 5811-5817, 2009.

Carrico, C. M., Bergin, M. H., Shrestha, A. B., Dibb, J. E., Gomes, L., and Harris, J. M.: The importance of carbon and mineral dust to seasonal aerosol properties in the Nepal Himalaya, Atmos. Environ., 37, 2811-2824, 2003.

Castro, L. M., Pio, C. A., Harrison, R. M., and Smith, D. J. T.: Carbonaceous aerosol in urban and rural European atmospheres: Estimation of secondary organic carbon concentrations, Atmos. Environ., 33, 2771-2781, 1999.

Chang, S.-C. and Lee, C.-T.: Secondary aerosol formation through photochemical reactions estimated by using air quality monitoring data in Taipei City from 1994 to 2003, Atmos. Environ., 41, 4002-4017, 2007.

Cheng, Y. F., Wiedensohler, A., Eichler, H., Su, H., Gnauk, T., Bruggemann, E., Herrmann, H., Heintzenber, J., Slanina, J., Tuch, T., Hu, M., and Zhang, Y. H.: Aerosol optical properties and related chemical apportionment at Xinken in Pearl River Delta of China, Atmos. Environ., 42, 6351-6372, 2008.

Chinnam, N., Dey, S., Tripathi, S. N., and Sharma, M.: Dust events in Kanpur, northern India: Chemical evidence for source and implications to radiative forcing, Geophys. Res. Lett., 33, L08803, doi:10.1029/ 2005GL025278, 2006.

Cong, Z., Kang, S., Dong, S., Liu, X., and Qin, D.: Elemental and individual particle analysis of atmospheric aerosols from high Himalayas, Environ. Monit. Assessment, 160, 323-335, 2008.

Cozic, J., Verheggen, B., Weingartner, E., Crosier, J., Bower, K. N., Flynn, M., Coe, H., Henning, S., Steinbacher, M., Henne, S., Collaud Coen, M., Petzold, A., and Baltensperger, U.: Chemical composition of free tropospheric aerosol for PM1 and coarse mode at the high alpine site Jungfraujoch, Atmos. Chem. Phys., 8, 407-423, doi:10.5194/acp-8-407-2008, 2008.

Decesari, S., Facchini, M. C., Carbone, C., Giulianelli, L., Rinaldi, M., Finessi, E., Fuzzi, S., Marinoni, A., Cristofanelli, P., Duchi, R., Bonasoni, P., Vuillermoz, E., Cozic, J., Jaffrezo, J. L., and Laj, P.: Chemical composition of $\mathrm{PM}_{10}$ and $\mathrm{PM}_{1}$ at the highaltitude Himalayan station Nepal Climate Observatory-Pyramid (NCO-P) (5079 m a.s.1.), Atmos. Chem. Phys., 10, 4583-4596, doi:10.5194/acp-10-4583-2010, 2010.

Dey, S., Tripathi, S. N., Singh, R. P., and Holben, B. N.: Influence of dust storms on aerosol optical properties over the Indo-Gangetic basin, J. Geophys. Res., 109, D20211, doi:10.1029/2004JD004924, 2004.

Dey, S. and Tripathi, S. N.: Retrieval of black carbon and specific absorption over Kanpur city, northern India during 2001-2003 using AERONET data, Atmos. Environ., 40, 445-456, 2006.

Dumka, U. C., Satheesh, S. K., Pant, P., Hegde, P., and Moorthy, K. K.: Surface changes in solar irradiance due to aerosols over central Himalayas, Geophys. Res. Lett., 33, L20809, doi:10.1029/2006GL027814., 2006.

Favez, O., Cachier, H., Sciare, J., Alfaro, S. C., El-Araby, T. M., Harhash, M. A., and Abdelwahab, M. M.: Seasonality of major aerosol species and their transformations in Cairo megacity, Atmos. Environ., 42, 1503-1516, 2008.

Gautam, R., Hsu, N. C., Lau, K.-M., Tsay, S.-C., and Kafatos, M.: Enhanced pre-monsoon warming over the Himalayan-Gangetic region from 1979 to 2007, Geophys. Res. Lett., 36, L07704, doi:10.1029/2009GL037641, 2009.

Geng, H., Park, Y., Hwang, H., Kang, S., and Ro, C.-U.: Elevated nitrogen-containing particles observed in Asian dust aerosol samples collected at the marine boundary layer of the Bohai Sea and the Yellow Sea, Atmos. Chem. Phys., 9, 6933-6947, doi:10.5194/acp-9-6933-2009, 2009.

Gobbi, G. P., Angelini, F., Bonasoni, P., Verza, G. P., Marinoni, A., and Barnaba, F.: Sunphotometry of the 2006-2007 aerosol optical/radiative properties at the Himalayan Nepal Climate Observatory-Pyramid (5079 m a.s.1.), Atmos. Chem. Phys., 10, 11209-11221, doi:10.5194/acp-10-11209-2010, 2010.

Gustafsson, Ö., Kruså, M., Zencak, Z., Sheesley, R. J., Granat, L., Engström, E., Praveen, P. S., Rao, P. S. P., Leck, C., and Rodhe, H.: Brown Clouds over South Asia: Biomass or Fossil Fuel Combustion?, Science, 323, 495-498, 2009.

Hegde, P., Pant, P., Naja, M., Dumka, U. C., and Sagar, R.: South Asian dust episode in June 2006: Aerosol observations in the central Himalayas, Geophys. Res. Lett., 34, L23802, doi:10.1029/2007GL030692, 2007.

Hegde, P., Pant, P. and Kumar, Y. B.: An integrated analysis of lidar observations in association with optical properties of aerosols from a high altitude location in central Himalayas, Atmos. Sci. Lett., 10, 48-57, 2008.

Hyvärinen, A. P., Lihavainen, H., Komppula, M., Sharma, V. P., Kerminen, V.-M., Panwar, T. S., and Viisanen, Y.: Continuous measurements of optical properties of atmospheric aerosols in Mukteshwar, Northern India, J. Geophys. Res., 114, D08207, doi:10.1029/2008JD011489, 2009.

Jacobson, M. Z.: Strong radiative heating due to the mixing state of black carbon in atmospheric aerosols, Nature, 409, 695-697, 2001.

Jethva, H., Satheesh, S. K. and Srinivasan, J.: Seasonal variability of aerosols over the Indo-Gangetic basin, J. Geophys. Res., 110, D21204, doi:10.1029/2005JD005938, 2005.

Kondo, Y., Miyazaki, Y., Takegawa, N., Miyakawa, T., Weber, R. J., Jimenez, J. L., Zhang, Q., and Worsnop, D. R.: Oxygenated and water-soluble organic aerosols in Tokyo, J. Geophys. Res., 109, D01203, doi:10.1029/2006JD007056, 2007.

Kumar, A., Sarin, M. M. and Sudheer, A. K.: Mineral and anthropogenic aerosols in Arabian Sea-atmospheric boundary layer: Sources and spatial variability, Atmos. Environ., 42, 5169-5181, 2008.

Kumar, A. and Sarin, M. M.: Mineral aerosols from western India: Temporal variability of coarse and fine atmospheric dust and elemental characteristics, Atmos. Environ., 43, 4005-4013, 2009.

Lelieveld, J., Crutzen, P. J., Ramanathan, V., Andreae, M. O., Bren- 
ninkmeijer, C. A. M., Campos, T., Cass, G. R., Dickerson, R. R., Fischer, H., De Gouw, J. A., Hansel, A., Jefferson, A., Kley, D., De Laat, A. T. J., Lal, S., Lawrence, M. G., Lobert, J. M., Mayol-Bracero, O. L., Mitra, A. P., Novakov, T., Oltmans, S. J., Prather, K. A., Reiner, T., Rodhe, H., Scheeren, H. A., Sikka, D. and Williams, J.: The Indian Ocean Experiment: Widespread air pollution from South and Southeast Asia, Science, 291, 10311036, 2001.

Liousse, C., Cachier, H. and Jennings, S. G.: Optical and thermal measurements of black carbon aerosol content in different environments: Variation of the specific attenuation cross-section, sigma $(\sigma)$, Atmos. Environ. A Gen., 27A, 1203-1211, 1993.

Menon, S., Hansen, J., Nazarenko, L., and Luo, Y.: Climate effects of black carbon aerosols in China and India, Science, 297, 22502253, 2002.

Menon, S., Koch, D., Beig, G., Sahu, S., Fasullo, J., and Orlikowski, D.: Black carbon aerosols and the third polar ice cap, Atmos. Chem. Phys., 10, 4559-4571, doi:10.5194/acp-10-4559-2010, 2010.

Miyazaki, Y., Kondo, Y., Sahu, L. K., Imaru, J., Fukushima, N., and Kanod, M.: Performance of A Newly Designed Continuous Soot Monitoring System (COSMOS), J. Environ. Monit., 10, 11091240, 2008.

Moffet, R. C. and Prather, K. A.: In-situ measurements of the mixing state and optical properties of soot with implications for radiative forcing estimates, Proc. Natl. Acad. Sci. U. S. A., 106, 11872-11877, doi/11810.11073/pnas.0900040106, 2009.

Pant, P., Hegde, P., Dumka, U. C., Sagar, R., Satheesh, S. K., Moorthy, K. K., Saha, A., and Srivastava, M. K.: Aerosol characteristics at a high-altitude location in central Himalayas: Optical properties and radiative forcing, J. Geophys. Res., 111, D17206, doi:10.1029/2005JD006768, 2006.

Prasad, A. K. and Singh, R. P.: Changes in Himalayan Snow and Glacier Cover Between 1972 and 2000, Eos Trans. AGU, 88, 33, doi:10.1029/2007EO330002, 2007.

Ram, K., Sarin, M. M., and Hegde, P.: Atmospheric abundances of primary and secondary carbonaceous species at two high-altitude sites in India: Sources and temporal variability, Atmos. Environ., 42, 6785-6796, 2008.

Ram, K. and Sarin, M. M.: Absorption coefficient and site-specific mass absorption efficiency of elemental carbon in aerosols from urban, rural and high-altitude sites in India, Environ. Sci. Technol., 43, 8233-8239, 2009.

Ram, K. and Sarin, M. M.: Spatio-temporal variability in atmospheric abundances of EC, OC and WSOC over northern India, J. Aerosol Sci., 41, 88-98, 2010.

Ram, K. and Sarin, M. M.: Day-night variability of EC, OC, WSOC and inorganic ions in urban environment of Indo-Gangetic Plain: Implications to secondary aerosol formation, Atmos. Envion., 45, 460-468, doi:10.1016/j.atmosenv.2010.09.055, 2011.

Ramana, M. V., Ramanathan, V., Podgorny, I. A., Pradhan, B. B., and Shrestha, B.: The direct observations of large aerosol radiative forcing in the Himalayan region, Geophys. Res. Lett., 31, L05111, doi:10.1029/2003GL018824, 2004.

Ramanathan, V., Chung, C., Kim, D., Bettge, T., Buja, L., Kiehl, J. T., Washington, W. M., Fu, Q., Sikka, D. R., and Wild, M.: Atmospheric brown clouds: Impacts on south Asian climate and hydrological cycle, Proc. Natl. Acad. Sci. U. S. A., 102, 53265333, 2005.
Ramanathan, V. and Ramana, M. V.: Persistent, widespread, and strongly absorbing haze over the Himalayan foothills and the Indo-Gangetic plains, Pure Appl. Geophys., 162, 1609-1626, 2005.

Ramanathan, V. and Carmichael, G.: Global and regional climate changes due to black carbon, Nature Geosci., 221-227, 2008.

Rastogi, N. and Sarin, M. M.: Quantitative chemical composition and characteristics of aerosols over western India: One-year record of temporal variability, Atmos. Environ., 43, 3481-3488, 2009.

Rengarajan, R., Sarin, M. M., and Sudheer, A. K.: Carbonaceous and inorganic species in atmospheric aerosols during wintertime over urban and high-altitude sites in North India, J. Geophys. Res., 112, D21307, doi:10.1029/2006JD008150, 2007.

Saarikoski, S., Timonen, H., Saarnio, K., Aurela, M., Järvi, L., Keronen, P., Kerminen, V.-M., and Hillamo, R.: Sources of organic carbon in fine particulate matter in northern European urban air, Atmos. Chem. Phys., 8, 6281-6295, doi:10.5194/acp-86281-2008, 2008.

Sagar, R., Kumar, B., Dumka, U. C., Moorthy, K. K., and Pant, P.: Characteristics of aerosol spectral optical depths over Manora Peak: A high-altitude station in the central Himalayas, J. Geophys. Res., 109, D06207, doi:10.1029/2003JD003954, 2004.

Schauer, J. J., Mader, B. T., Deminter, J. T., Heidemann, G., Bae, M. S., Seinfeld, J. H., Flagan, R. C., Cary, R. A., Smith, D., Huebert, B. J., Bertram, T., Howell, S., Kline, J. T., Quinn, P., Bates, T., Turpin, B., Lim, H. J., Yu, J. Z., Yang, H., and Keywood, M. D.: ACE-Asia intercomparison of a thermal-optical method for the determination of particle-phase organic and elemental carbon, Environ. Sci. Technol., 37, 993-1001, 2003.

Schuster, G. L., Dubovik, O., Holben, B. N., and Clothiaux, E. E.: Inferring black carbon content and specific absorption from Aerosol Robotic Network (AERONET) aerosol retrievals, J. Geophys. Res., 110, D10S17, doi:10.1029/2004JD004548, 2005.

Sharma, S., Brook, J. R., Cachier, H., Chow, J., Gaudenzi, A., and Lu, G.: Light absorption and thermal measurements of black carbon in different regions of Canada, J. Geophys. Res., 107(D24), 4771, doi:10.1029/2002JD002496, 2002.

Turpin, B. J. and Lim, H.-J.: Species contributions to $\mathrm{PM}_{2.5}$ mass concentrations: Revisiting common assumptions for estimating organic mass, Aerosol Sci. Technol., 35, 602-610, 2001.

Venkataraman, C., Habib, G., Eiguren-Fernandez, A., Miguel, A. H., and Friedlander, S. K.: Residential biofuels in South Asia: Carbonaceous aerosol emissions and climate impacts, Science, 307, 1454-1456, 2005.

Weber, R. J., Sullivan, A. P., Peltier, R. E., Russell, A., Yan, B., Zheng, M., de Grouw, J., Warneke, C., Brock, C., Holloway, J. S., Atlas, E. L., and Edgerton, E.: A study of secondary organic aerosol formation in the anthropogenicinfluenced southeastern United States, J. Geophys. Res., 112, D13302, doi:10.1029/2007JD008408, 2007.

Yasunari, T. J., Bonasoni, P., Laj, P., Fujita, K., Vuillermoz, E., Marinoni, A., Cristofanelli, P., Duchi, R., Tartari, G., and Lau, K.-M.: Estimated impact of black carbon deposition during premonsoon season from Nepal Climate Observatory - Pyramid data and snow albedo changes over Himalayan glaciers, Atmos. Chem. Phys., 10, 6603-6615, doi:10.5194/acp-10-6603-2010, 2010. 
Zhang, Q., Jimenez, J. L., Canagaratna, M. R., Allan, J. D., Coe, H., Ulbrich, I., Alfarra, M. R., Takami, A., Middlebrook, A. M., Sun, Y. L., Dzepina, K., Dunlea, E., Docherty, K., DeCarlo, P. F., Salcedo, D., Onasch, T., Jayne, J. T., Miyoshi, T., Shimono, A., Hatakeyama, S., Takegawa, N., Kondo, Y., Schneider, J., Drewnick, F., Borrmann, S., Weimer, S., Demerjian, K., Williams, P., Bower, K., Bahreini, R., Cottrell, L., Griffin, R. J., Rautiainen, J., Sun, J. Y., Zhang, Y. M., and Worsnop, D. R.: Ubiquity and dominance of oxygenated species in organic aerosols in anthropogenically-influenced Northern Hemisphere midlatitudes, Geophys. Res. Lett., 34, L13801, doi:10.1029/2007GL029979, 2007. 